\title{
A COMUNICAÇÃO ORGANIZACIONAL COMO VISÃO ESTRATÉGICA UTILIIZANDO 0 EMPOWERMENT COMO FATOR DETERMINANTE PARA O DESENVOLVIMENTO DE UMA ORGANIZAÇÃO
}

Carlos Navarro Fontanillas

Universidade Federal do Rio de Janeiro (UFRJ)

navarro@pep.ufrj.br

\section{Bruno da Rocha Palmieri}

Universidade Federal Fluminense (UFF)

brunopalmieri85@yahoo.com.br

Janaína Tannus de Oliveira

Universidade Federal Fluminense (UFF)

janatannus@gmail.com

\section{RESUMO}

A comunicação organizacional, aliada ao empowerment como ferramenta de melhoria a qualidade e produtividade, proporciona aos tomadores de decisão um elemento de caráter estratégico para a gestão e administração das organizações modernas. $\mathrm{O}$ artigo demonstra as ferramentas que interagem entre o ambiente interno e fatores exógenos relacionados as empresas, como: seu público, mercado potencial e a sociedade. Não obstante, é a comunicação que gera valor competitivo, construindo uma cultura organizacional coerente aos valores corporativos. O uso do empowerment consiste na delegação de autoridade e de responsabilidade. Denota-se o uso da descentralização de poderes na cadeia hierárquica de uma organização, conferindo autonomia aos colaboradores de modo que eles se mostrem aptos a diagnosticar, analisar e propor soluções no dia-a-dia.

Palavras-chave: Processo decisório. Tomada de decisão. Empowerment.

\begin{abstract}
The organization, allied communication to empowerment as improvement tool the quality and productivity, provides to the decision borrowers an element of strategically character for the management and administration of the modern organizations. The article demonstrates the tools that interact between the internal environment and exogenous factors related the companies, as: its public, potential market and the society. In another way, it is the communication that generates competitive value, constructing a coherent organizational culture to the corporative values. The use of empowerment consists of the delegation of authority and responsibility. The use of the decentralization of being able in the hierarchic chain of an organization, conferring autonomy to the way collaborators is denoted that they reveal apt to diagnosis, to analyze and to consider solutions in day-by-day.
\end{abstract}

Keywords: Decision process. Taking of decision. Empowerment. 


\section{INTRODUÇÃO}

0 mundo empresarial torna-se cada vez mais complexo e globalizado. Por isso, exigese que os tomadores de decisão sejam profissionais cada vez mais bem informados e estrategistas. Para obter esse fim, vale-se do velho ditado "Duas cabeças pensam melhor do que uma", e surge então, o conceito do processo de decisão em grupo. Nesse contexto, vários intervenientes participam da escolha da melhor decisão, o que pode vir a aumentar as chances de acerto, mas nem sempre esta é uma tarefa fácil.

As transformações sócio-econômicas e os avanços tecnológicos ocorridos no mundo nas últimas décadas, como internet, a globalização dos mercados, as novas tecnologias da informação e o aumento da competitividade, obrigaram as organizações a reavaliar e ajustar processos, estruturas, formas de comercialização e muitos outros aspectos e paradigmas até então pouco mutáveis ou que praticamente estavam estagnados. Este movimento ampliou a necessidade de compreensão e intercâmbio com mercados e públicos de interesse que se apresentam de forma volátil, em constante transformação, e trouxe consigo uma excelente oportunidade para o aprimoramento das atividades de comunicação no ambiente corporativo, fazendo-o assumir posição estratégica nas organizações, uma vez que tanto interna quanto externamente é a comunicação o instrumento mais capacitado para o intercâmbio de informações nas empresas.

Se considerarmos a comunicação como um dos elementos que formam a base dos relacionamentos humanos, é possível afirmar que esta é então uma prática de extrema importância a todo e qualquer ambiente em que haja interação social, incluindo-se as organizações, visto seus objetivos, papéis e tarefas. Atualmente, as exigências que os consumidores impõem as organizações não dizem respeito somente a qualidade e ao preço de seus produtos ou serviços, mas também a postura crítica que assumem diante da realidade do mundo dos negócios e ao seu papel como agente transformador e responsável pelo desenvolvimento da sociedade. A imagem que uma organização apresenta, defende e sustenta, é hoje fator crítico para sua sobrevivência, na medida em que é por meio dela que seus diversos públicos são informados sobre o que ela é, faz e pretende.

Diante disso podemos notar que a comunicação nas empresas tornou-se um instrumento prático de transparência, diálogo e negociação, responsável pela integração com seus stakeholders e/ou representantes de esferas governamentais. Não obstante, é de suma importância que as organizações estejam atentas a postura que adotam diante da comunicação, nesse tempo em que a informação é fator de produtividade e competitividade. Estar atento também para notar que mais do que efetuar grandes investimentos em tecnologias de transmissão, retenção e tratamento de dados, torna-se imprescindível que as empresas que pretendam sobreviver ao futuro, criem mecanismos que transformem a comunicação em elemento fundamental e básico para o planejamento estratégico e um diálogo aberto no ambiente organizacional, o que tende a aumentar de forma significativa seu poder competitivo em relação aos concorrentes menos preparados.

A mistura de idéias pode gerar alternativas inovadoras e soluções criativas, ou então, conflitos pessoais e divergências de opiniões. Para que o resultado desta técnica tenha maiores chances de ser positivo, são apresentadas nas páginas seguintes, após uma breve definição do processo decisório, algumas ferramentas utilizadas nos processos de decisão em grupo.

\section{O PROCESSO DECISÓRIO}


Decisão é o processo de escolha dentre alternativas existentes a serem colocadas em práticas. Para que haja decisão é necessário haver os seguintes elementos:

- Tomador de decisões: pessoa ou grupo de pessoas que adota uma alternativa futura de ação;

- Objetivos a serem alcançados;

- Preferências e critérios para o julgamento das alternativas;

- Estratégia, que reflete as diretrizes tomadas pelo decisor a fim de alcançar seus objetivos;

- Situação, que são as condições ambientais que interferem tanto na estratégia quanto nos objetivos para a tomada de decisão;

- Resultado: conseqüência final da estratégia adotada.

O processo de decisão é complexo e abrange diversas etapas, como pode ser observado no esquema abaixo. Alguns autores asseveram que este processo consiste em sete etapas, contudo há a possibilidade de se estender a quantidade de etapas a fim de se obter maior eficácia. É necessário que não haja pressão, pois, da mesma forma como é possível ampliar etapas, também é possível que algumas delas sejam inibidas, caso haja pressão de solução imediata.

Esquema 1 - Etapas do Processo de Decisão

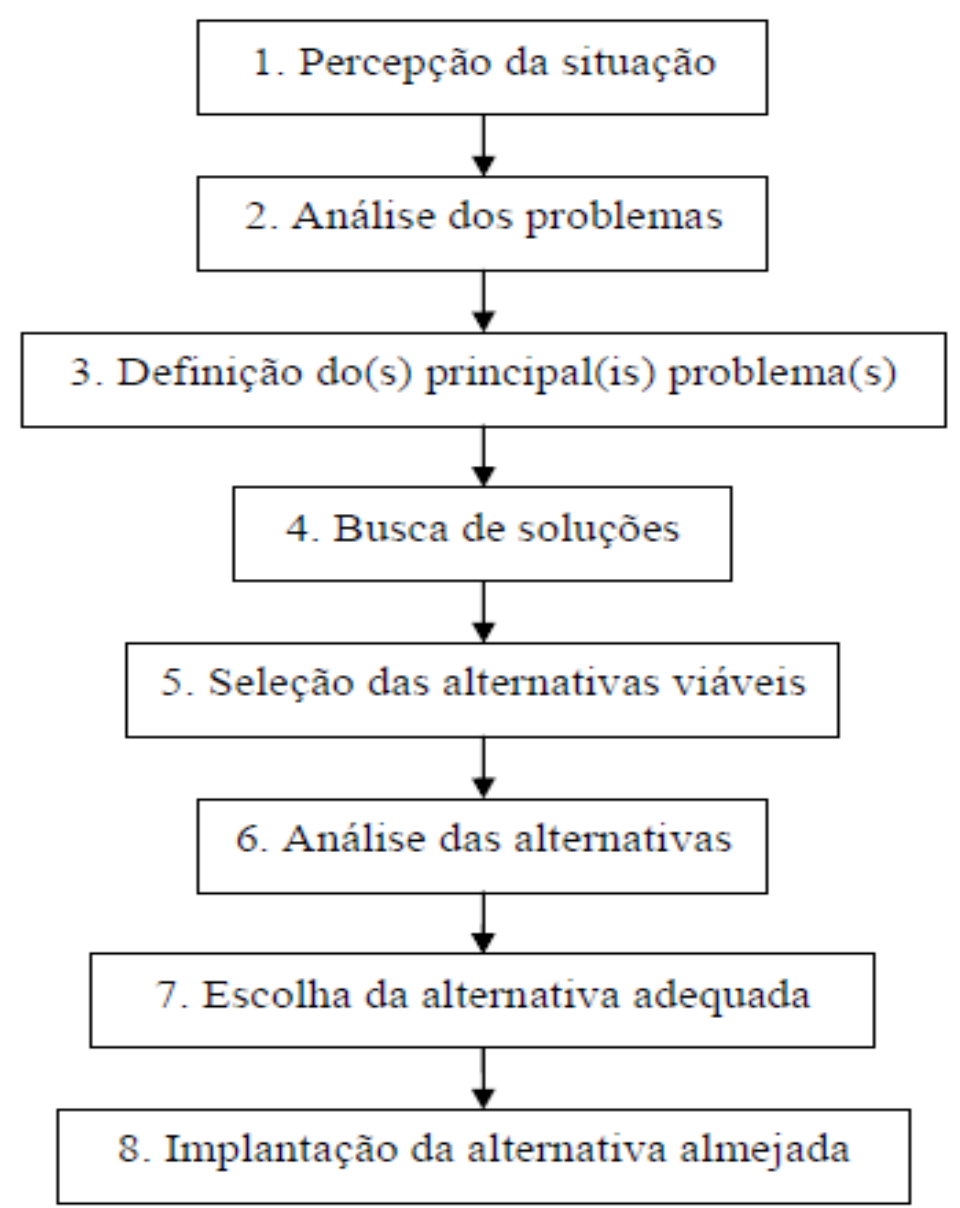

Fonte: Desenvolvimento Próprio 
Para melhor compreensão das decisões e com o intuito de explicar o comportamento humano nas organizações, Herbert Alexander Simon, da Escola Superior de AdministraçãoIndustrial do Carnegie Institute of Technology, criou a Teoria das Decisões. Segundo a Teoria, o tomador de decisões deve conhecer todas as informações existentes a fim de obter perfeita análise da situação. Contudo, é impossível que haja tamanha coleta de dados e, por isso, existe uma racionalidade limitada.

Outro ponto que destaca-se, baseia na inexistência da decisão perfeita, uma vez que uma das decisões pode ser melhor que outras, porém, todas apresentam inconsistências devido à racionalidade limitada. Então, as escolhas devem ser feitas pelo critério eficiência, ou seja, alcance dos objetivos com utilização de recursos mínimos. Ao escolher uma das alternativas, abandona-se as demais e, desta forma, não há como alcançar plenamente os objetivos.

\section{TIPOS DE COMUNICAÇÃO}

- Comunicação mercadológica tem como objetivo divulgar os produtos e/ou serviços da organização, visando o aumento de vendas ou simplesmente sua estabilização no mercado. As principais ferramentas da comunicação mercadológica são a propaganda, a promoção de vendas, a venda pessoal, o merchandising, os eventos e o marketing direto de relacionamentos.

- Comunicação institucional cuja finalidade é conquistar a credibilidade e a confiança do público de seu interesse, divulgando a filosofia, a missão, os valores e princípios da organização, retratados em suas políticas e práticas. Para isso, utiliza ferramentas como a identidade e a imagem corporativa, a propaganda institucional, o jornalismo empresarial, a assessoria de imprensa, a editoração eletrônica, o marketing social, cultural e esportivo, bem como as relações públicas.

- Comunicação interna, voltada a todos os colaboradores da organização, tem como objetivo promover a integração dos funcionários, a troca de informação, o estímulo as experiências e o diálogo. Para tanto, desenvolve programas de prevenção de acidentes, aperfeiçoamento profissional, campanhas de criatividade e competitividade.

- Comunicação administrativa tem como preocupação a unificação da linguagem no que diz respeito aos fluxos de serviços, aos níveis hierárquicos, as redes formais e informais de comunicação, com o objetivo de orientar, atualizar e ordenar o fluxo de atividades funcionais da organização. Fazem parte da comunicação administrativa as normas, as instruções, as portarias, os memorandos, as cartas técnicas, os regulamentos, os avisos, os índices, as taxas, a racionalização de redes entre outras.

A comunicação como instrumento estratégico representa atividade fundamental da administração, visto que é um dos poucos meios capazes de permitir a troca de informações e de sentido, compreendida como algo que necessita ser compartilhado, entendido e dialogado, entre os colaboradores de uma empresa e entre estes e o mercado, ou seja, seus diversos públicos. Dentre as mais diversas formas de interação que ocorrem no ambiente das organizações, as que acontecem com maior freqüência e as quais se dá maior importância são as que estão, de alguma forma, relacionadas aos fluxos de troca de informação, isso porque são esses caminhos de dados e conhecimento que permitem que a organização permeie aos ambientes de sua atuação, tanto interna quanto de forma exógena.

Necessita-se adequar e trabalhar com máxima eficiência, sob pena de não solucionar ou até mesmo causar graves danos a perfeita atividade das empresas. Para tal, há que se atentar para 
as variáveis que podem interferir de forma negativa no bom andamento do processo comunicativo, dentre, as quais a motivação, a credibilidade da fonte, a habilidade de comunicar e o clima organizacional.

\section{PROCESSO DE DECISÃO EM GRUPO}

Ao optar-se por incentivar em uma empresa o Processo de Decisão em Grupo, o gestor deve estar ciente das dificuldades com que irá se deparar pelo caminho. Mesmo em grupos limitados e homogêneos surgem discordâncias nas opiniões apresentadas, o que pode gerar conflitos entre seus membros. Serão apresentadas a seguir algumas ferramentas facilitadoras do Processo Decisório em Grupo.

\section{Empowerment}

O empowerment ou empoderamento é uma ferramenta que passou a ser utilizada em meados da década de 1980 para delegação de autoridades e responsabilidades pelas tomadas de decisão. Ela proporciona um fortalecimento do papel de pessoas e equipes. De acordo com o dicionário americano Webster's Ninth, suas origens sociais remetem ao século XVII e suas raízes se modulam nas bases filosófica, sociológica e religiosa.

Esta ferramenta propõe a descentralização de poderes na cadeia hierárquica e uma maior autonomia dos funcionários. Com isso, pretende que os integrantes da equipe tenham maior grau de envolvimento com o trabalho desempenhado e que se estabeleçam relações de confiança entre eles.

A aplicação do empowerment em equipes tem como principal vantagem a criação de um centro de sinergias. Grupos sem sinergia e pouco alinhados podem apresentar bons empenhos individuais, mas os resultados da equipe não serão satisfatórios. Por outro lado, os grupos sinérgicos orientam os desempenhos individuais para uma única direção e evitam desperdícios de recursos através da coesão de objetivos.

Para que a implementação da ferramenta possa trazer os resultados satisfatórios esperados, faz-se necessária a adoção de certas medidas, tais como: fornecer feedbacks regularmente, inibir iniciativas individuais, potencializar a comunicação entre os membros da equipe e estabelecer os limites a serem respeitados.

Tendo em vista a eficácia da ferramenta empowerment, observa-se que esta gera respostas rápidas aos consumidores, mantém os funcionários motivados com suas funções e promove, ainda, a melhoria da imagem institucional. Destarte, faz-se necessário alguns investimentos por parte da empresa. A tabela abaixo apresenta alguns pontos de trade-off da abordagem empowerment. 
A comunicação organizacional como visão estratégica utilizando o empowerment como fator determinante para o desenvolvimento de uma organização

Tabela 1 - Trade-off da abordagem Empowerment

\begin{tabular}{|c|c|c|}
\hline Fator & $\begin{array}{c}\text { Abordagem de não- } \\
\text { empowerment }\end{array}$ & Abordagem de empowerment \\
\hline $\begin{array}{c}\text { Estratégia básica de } \\
\text { negócios }\end{array}$ & Custo baixo, volume alto & Diferenciação customizada, personalizada \\
\hline $\begin{array}{c}\text { Ligações com } \\
\text { consumidor }\end{array}$ & Transação, curto prazo & Relacionamento, longo prazo \\
\hline Tecnologia & Rotineira, simples & Não rotineira, complexa \\
\hline Ambiente de negócios & Previsivel, poucas surpresas & Imprevisivel, muitas surpresas \\
\hline Tipos de pessoas & $\begin{array}{c}\text { Gerestes autocráticos, } \\
\text { necessidades de crescimento, } \\
\text { baixas necessidades sociais e } \\
\text { habilidades interpessoais } \\
\text { fracas }\end{array}$ & $\begin{array}{c}\text { Gerentes democráticos, empregados com } \\
\text { necessidades de crescimento altas, altas } \\
\text { necessidades sociais e habilidades } \\
\text { interpessoais fortes }\end{array}$ \\
\hline
\end{tabular}

Fonte: SLACK, N. Administração da Produção, Segunda Edição, Editora Atlas, 2002

\section{Sistemas de informação}

Os Sistemas de Informação Gerencial (SIG), também conhecidos por Management Information System (MIS), auxiliam no processo de decisão utilizando sistemas computacionais que geram informações necessárias e mais fidedignas aos decisores. Isto é feito através da criação de banco de dados integrados, além de sistemas de processamento de dados e canais de comunicação. Esta ferramenta possui maior aplicabilidade nas etapas de planejamento e controle.

Existem quatro tipos de estruturas para o SIG, que são: estrutura centralizada; estrutura hierarquizada; estrutura distribuída e estrutura descentralizada. A fim de ilustrar mais claramente suas diferenças, a tabelas abaixo apresenta todos os tipos.

Tabela 2 - Estruturas do SIG

\begin{tabular}{|c|c|c|c|c|}
\hline & $\begin{array}{c}\text { Estrutura } \\
\text { Centralizada }\end{array}$ & $\begin{array}{c}\text { Estrutura } \\
\text { Hierarquizada }\end{array}$ & $\begin{array}{l}\text { Estrutura } \\
\text { Distribuída }\end{array}$ & $\begin{array}{c}\text { Estrutura } \\
\text { Descentralizada }\end{array}$ \\
\hline Estrutura & $\begin{array}{l}\text { Computador central } \\
\text { (mainframe) }\end{array}$ & $\begin{array}{c}\text { De acordo com as } \\
\text { necessidades dos } \\
\text { niveis }\end{array}$ & $\begin{array}{l}\text { Computadores } \\
\text { separados }\end{array}$ & $\begin{array}{l}\text { Divisão de } \\
\text { computadores }\end{array}$ \\
\hline Vantagens & $\begin{array}{l}\text { Baixo custo, } \\
\text { simplicidade, } \\
\text { eficiência de } \\
\text { recursos de } \\
\text { processamento de } \\
\text { dados } \\
\end{array}$ & $\begin{array}{l}\text { Informações de } \\
\text { acordo com as } \\
\text { necessidades dos } \\
\text { níveis } \\
\text { correspondentes }\end{array}$ & $\begin{array}{l}\text { Sistema múltiplo } \\
\text { com linhas de } \\
\text { comunicação }\end{array}$ & $\begin{array}{c}\text { Maior segurança } \\
\text { e rapidez de } \\
\text { informação }\end{array}$ \\
\hline Desvantagens & $\begin{array}{l}\text { Elevado tempo de } \\
\text { resposta às } \\
\text { inovações }\end{array}$ & $\begin{array}{l}\text { Comprometimento na } \\
\text { comunicação das } \\
\text { informações }\end{array}$ & $\begin{array}{c}\text { Estrutura de alto } \\
\text { custo }\end{array}$ & $\begin{array}{l}\text { Estrutura de } \\
\text { mais elevado } \\
\text { custo }\end{array}$ \\
\hline
\end{tabular}


O SIG engloba o Sistema de Suporte à Decisão (DSSs), cuja finalidade é apoiar as decisões. Para que assim seja feito, é fundamental que as informações necessárias sejam armazenadas, processadas e apresentadas aos tomadores de decisão, de modo a ajudá-los a compreender o porquê e as conseqüências das escolhas das alternativas.

Nesse contexto é cada vez mais freqüente a utilização de sistemas eletrônicos de suporte à decisão em grupo. Eles são capazes de combinar tecnologias informáticas, algorítmicas e de comunicação que tornam mais fáceis o processamento dos dados e a interação do grupo, e por isso são consideradas ferramentas essenciais para a resolução de problemas e a tomada de decisão.

\section{Brainstorming}

O Brainstorming consiste numa técnica de dinâmica em grupo utilizada para incentivar a liberação das idéias de seus participantes, sem inibições ou restrições. A diversidade das idéias expostas permite que os participantes evoluam em seus raciocínios e passem a considerar novas possibilidades que haviam esquecido ou negligenciado. Esta é uma técnica direcionadora de idéias, usada por equipes para guiar oportunidades de melhoria em um espaço de tempo limitado. Alguns benefícios que a ferramenta proporciona à tomada de decisão em grupo:

- Fornece rapidamente um grande volume de idéias;

- Estimula a criatividade e a inovação;

- Estimula o envolvimento dos participantes;

- Faz desenvolver o sentimento de propriedade;

- Gera input para outras ferramentas.

Para iniciar a dinâmica, é necessário um ponto de partida e uma estratégia de evolução da reunião, quando então os participantes expõem suas idéias, de forma ordenada, e se utilizam das diferenças de opiniões para chegar a um consenso. Esta é uma das ferramentas mais populares e eficazes para a tomada de decisões em grupo. Admite-se que para alcançar certa autonomia, ferramentas de cunho quantitativo deverão participar desse processo a fim de corroborar com o método utilizado.

\section{Pesquisa Operacional}

A Pesquisa Operacional (PO) também pode ser utilizada como ferramenta para a tomada de decisões em grupo. Normalmente, para a resolução de um problema de alta complexidade, que envolva muitas partes ou muitas áreas diferentes, é necessária uma abordagem fundamentada no emprego de um método de decisão multicritério. A metodologia de Apoio Multicritério à Decisão surgiu dentro da Pesquisa Operacional com o intuito de auxiliar decisões quem envolvam não apenas uma, mas muitas variáveis, em um ambiente considerado complicado.

Tomemos como exemplo um problema que envolva os diversos setores de uma empresa: Marketing, Produção, Finanças, RH, Engenharia e Administração, dentre outros. Os decisores de cada área devem se reunir com um facilitador cuja função é conduzir o encontro e moderar as discussões, dando assistência ao grupo a fim de obter a melhor decisão possível. 
No encontro, todos os critérios devem ser expostos, sejam eles individuais ou comuns. Os critérios são, então, apresentados numa matriz de avaliação e julgados individualmente por cada membro do grupo. 0 método requer avaliações numéricas e, desta forma, escalas qualitativas terão que ser transformadas em escalas quantitativas. Ao final, todos os decisores têm uma visão melhor do problema e torna-se mais fácil apontar a sua melhor solução.

\section{CONSIDERAÇÕES FINAIS}

No presente trabalho, procuramos demonstrar a importância das contribuições que cada escola apresenta para a caracterização da comunicação organizacional. A partir desse estudo e análise, pode-se estabelecer um processo de tomada de decisão baseado em quatro pilares:

- empowerment;

• sistema de informação;

- brainstorming;

- pesquisa operacional

O trabalho apresentou em ordem, a configuração e os conceitos clássicos de comunicação organizacional, os novos requisitos do mercado para tal, e as disfunções deste conjunto de fatores. Existe ainda um grande espaço entre a atual prática do empowerment nas organizações ao esperado pelo mercado.

Não obstante, esta diferença não é crônica, mas gerada pela mudança da demanda do mercado. Em sua justificativa, o estudo ressaltou que a adoção de metodologias com base no empowerment provavelmente seria uma grande evolução para a construção do conhecimento e a geração de conteúdos informacionais mais confiáveis, num contexto de incertezas e entropias para a tomada de decisão.

\section{REFERÊNCIAS BIBLIOGRÁFICAS}

CHIAVENATO, Idalberto. Introdução à Teoria Geral da Administração. 7a edição, Editora Campus, Rio de Janeiro, 2004.

CHIAVENATO, Idalberto. Administração dos Novos Tempos. 2a edição, Editora Campus, Rio de janeiro, 2006.

SLACK, Nigel. Administração da Produção. 2ª edição, Editora Atlas, São Paulo, 2007.

PORTER, E. Michael. Estratégia Competitiva: Técnicas para análise de indústria e da concorrência. Trad. Elizabeth Maria de P. Braga. 7a edição, Editora Campus, Rio de Janeiro, 1996.

SAATY, TL. Método de Analise Hierárquica. Ed. Makron, São Paulo, 1991.

OLIVEIRA, Djalma de Pinho Rebouças. Administração de Processos. Editora Atlas, São Paulo, 2006. 
MOREIRA, D.A. Administração da Produção e Operações. Editora Thomson, São Paulo, 1993.

MARANHÃO, Mauriti. O Processo Nosso de Cada Dia. Editora Qualitymark, Rio de Janeiro, 2004. 